\title{
Structure System on Urban Public Crisis Management
}

\author{
Yongchang Ren \\ College of Information Science and Technology, Bohai University, Jinzhou, 121013, China \\ 1213552916@qq.com
}

Keywords: urban management; public crisis; crisis management; structure system

\begin{abstract}
Enhance the urban crisis management ability, prevent the emergencies, protect the city's security, and maintain the sustainable development of the city, which has become a major issue of urban management. In this paper, it analyzes the problems of urban public crisis management system, expounds the necessity of constructing the urban public crisis management system, combined with the experience of the former, and constructs the structure system of urban public crisis management. Structural systems include "decision-making mechanism, linkage mechanism, financial support, early warning mechanism, rescue mechanism, organizational leadership, information security, material support, legal protection, performance evaluation" and so on. The research content of this paper is to solve the core problem of urban crisis management, which is very important to strengthen the urban crisis management and improve the crisis management ability.
\end{abstract}

\section{Introduction}

Improving the quality of human life by modern urban development. Urbanization has become an important symbol to measure the level of national modernization. The city brings people a better life, but also brings a more serious crisis. All kinds of natural disasters and unexpected events have great influence on the safety of life and property, social economic and political order and national security [1]. The establishment of standardized urban emergency management mechanism, a fast, comprehensive and correct response to all kinds of disasters, to reduce the impact of the crisis and create a sustainable development of the urban environment, has become a key issue to be resolved in the urban strategic management. In order to effectively deal with the urban crisis, improve the level of urban governance, maintain social stability, we must strengthen the study of urban crisis management, learn from and draw on foreign advanced theory and practice experience, to provide scientific and reasonable policy recommendations for the effective management of urban crisis. In this paper, the urban crisis management as the core content, focus on the structure of China's urban crisis management system construction, for the urban crisis management and accumulation of useful empirical data, scientific and systematic analysis of the urban crisis management, and to improve the level of urban management has theoretical and practical significance.

\section{Existing Problems of Urban Public Crisis Management Structure System}

Chinese cities have accumulated some experience in the crisis response to the formation of the public crisis management system, which plays a great role in the protection of public safety, to mitigate the crisis, protect the interests of the state. But the existing crisis management system is lack of integration, in the coordination of social security aspects of the multi-level, multi type integrated crisis management system also exist many problems [2,3].

(1) Government crisis management command system is not perfect. All levels of government are not independent of the permanent crisis management command. When the crisis comes, established a temporary agency, send the relevant personnel of the various departments, relying on the relevant functional departments of the temporary work agencies, after the crisis repeal these institutions, the dissolution of the personnel. This model has a lot of disadvantages, temporary agencies with short-term emergency nature, it is a passive management mode, which is not conducive to the prediction of crisis events, early warning, the impact of the crisis management efficiency. Due to 
the lack of a unified crisis management command organization, it can not be integrated coordination of various government departments, and hence can not effectively integrate social resources.

(2) The use of resources to deal with the public crisis is not reasonable. The resources to deal with the public crisis are mainly provided by the government, while the government is not enough to the total amount of resources, which directly leads to the shortage of emergency resources. On the one hand, the existing emergency facilities and rescue equipment are backward, the government has not enough funds to improve and update; on the other hand, the vast majority of enterprises on the importance of the crisis management is not enough, ignoring the emergency equipment and maintenance. In the resource management, the Department decentralized management, which is responsible for the management of the corresponding emergency resources, there is no unified command, efficient, coordinated and orderly management system of emergency resources.

(3) Lack of crisis management plan and the overall strategic planning. The public crisis warning system, on the one hand, collects and captures the symptoms of the crisis, analyzes the information and predicts the possible crisis. On the other hand, the information is released to the public and the relevant personnel and departments. Therefore, the crisis prevention is more meaningful than the crisis management. Early informed and timely warning signal is the effective way to reduce the loss. In the public crisis management, the government lacks the warning and the plan, only acts as the role of "fire fighting", and has no long-term strategic plan, which is often used in the crisis to increase the cost of crisis management.

(4) Public information disclosure system in the process of crisis management. Influenced by the traditional ideas, the crisis information collection is often taken to suppress, concealment and other practices, coupled with government officials from the consideration of the performance, the crisis information is not quickly feedback, missed the best time to deal with the crisis. Government did not timely disclosure of the truth and the timely provision of accurate and reliable information, the news media is unable to accurately report, citizens can only rely on unreliable gossip, prone to panic. The crisis information slow newspaper, omission and misstatement, miss the effective prevention, pre control, forecast and control the crisis of the favorable opportunity and influence to the crisis to make the scientific decision.

\section{Necessity of Construction on Urban Public Crisis Management Structure System}

Whether the effective response to all kinds of crisis events, not only affects the stability and development of the political economy, but also related to the government's credibility and image in the hearts of the people. Therefore, to strengthen the government crisis management, improve China's government crisis management system is the current level of our government must attach great importance to the problem.

(1) Social and economic development factors. The level of economic development is usually in the level of economic development, industrialization and the level of gross national product, national per ca-pita income level and health care standards for the evaluation criteria, which used to analyze the relationship between the social and political stability. China is in the social transition period, according to the international law of social development, when a country or region's per capita GDP in the development phase of 1000 to 3000 U.S. dollars, the economy is easy to disorder, social easy to lose order, are a critical period of social ethics need to adjust the reconstruction, but also the crisis prone period.

(2) Lack of traditional moral culture. After the impact of the development of the western society and several cultural changes, the traditional Confucian thought system is gradually weakened, there is a certain degree of belief crisis. In the fast development of social economy, the education development lags behind. The social atmosphere of corruption causes the moral foundation to shake. The life style of the network times has seriously impacted the old moral standard system. The original system in the rapid changes with the social life of the disorder, resulting in the serious deviation and the deviation of people in concrete action, both may cause the crisis and lead to the intensification of the crisis. 
(3) Social pressure increase. With the growing competition mechanism, people in the field of ethics, values, behavior, interpersonal relations and other areas of conflict and pressure is growing, the probability of psychological frustration increased, the psychological imbalance, more and more psychological disorders. The huge social pressure and conflicts lead to some social and anti human behavior. Therefore, it is necessary for the government to strengthen the scientific nature of crisis management, from the perspective of psychology, ethics, etc..

\section{Construction on Urban Public Crisis Management Structure System}

The urban public crisis management structure system is a hierarchical structure, which is composed of multiple objective systems, as shown in Fig. 1 [4-6].

\begin{tabular}{|l|c|c|c|c|}
\hline $\begin{array}{c}\text { Decision-making } \\
\text { mechanism of public } \\
\text { crisis }\end{array}$ & $\begin{array}{c}\text { Linkage mechanism of } \\
\text { public crisis }\end{array}$ & $\begin{array}{c}\text { Financial support of } \\
\text { public crisis }\end{array}$ & $\begin{array}{c}\text { Early warning } \\
\text { mechanism of public } \\
\text { crisis }\end{array}$ \\
\cline { 3 - 4 } $\begin{array}{c}\text { Rescue mechanism of } \\
\text { public crisis }\end{array}$ & $\begin{array}{c}\text { Structure system on urban } \\
\text { public crisis management }\end{array}$ & $\begin{array}{c}\text { Organizational } \\
\text { leadership of public } \\
\text { crisis }\end{array}$ \\
\hline $\begin{array}{c}\text { Information security of } \\
\text { public crisis }\end{array}$ & $\begin{array}{c}\text { Material support of } \\
\text { public crisis }\end{array}$ & $\begin{array}{c}\text { Legal protection of } \\
\text { public crisis }\end{array}$ & $\begin{array}{c}\text { Performance } \\
\text { evaluation of public } \\
\text { crisis }\end{array}$ \\
\hline
\end{tabular}

Fig. 1. Structure system on urban public crisis management

(1) Public crisis decision-making mechanism. Public crisis decision-making is the process of crisis, in the limited time, resources, manpower and other constraints to complete the response to the crisis of specific measures to the fastest speed to make the decision. Decision-making body is not only the government, but also includes the non governmental organizations, the media, the public, including the decision-making group. This is one of the important differences between the modern crisis decision making and the traditional crisis decision making. Through the crisis decision-making, not only effectively control the crisis, and to block the occurrence and expansion of the crisis, reduce the risk of the crisis, but also through the prediction and recognition of the crisis, and actively adjust and control the crisis, and promote the crisis in a favorable direction. Decision making is the basis and guarantee for the realization of the goal and the ultimate goal of the crisis decision making.

(2) Linkage mechanism of public crisis. Coordination linkage mechanism is the communication and complement between the government and the social organization in the process of crisis management, and through the communication and information exchange, the integration of resources, the common action, and the coordination of the operational mode of the crisis. Coordination linkage mechanism is an important part of the crisis management system. The construction of complete functions, perfect facilities, comprehensive organization and coordination of the linkage mechanism, the effective integration and play various social resources, to adapt to the needs of the new situation and improve the public crisis management capabilities.

(3) Financial support for public crisis. As the macro economic regulation department, the financial department is responsible for the allocation of public goods and public services. The financial sector through the improvement of the system, adjust the structure of expenditure, integration of resources, to ensure that emergency management funds. The financial department, as the social public resources distribution management department, should strive to improve the emergency management of public products and public service quality, solve the market can not play a role in the field. Through optimizing and adjusting the structure of financial expenditure, increasing the input of financial emergency management, and ensuring the working funds of 
emergency management department, the emergency rescue fund is allocated in time to ensure the timely arrival of relief supplies.

(4) Public crisis early warning mechanism. Public crisis warning is the main body of crisis management. According to the phenomenon of crisis and data, the use of logical reasoning and scientific forecasting methods, the constraints of the crisis, the development trend and the evolution of the law, and make a warning signal, so that the government and the people to understand the situation in advance, in order to take the strategy to prevent adverse consequences. Crisis warning is the first line of defense in public crisis management, the establishment of the early warning mechanism of public crisis management, which is to make the crisis early warning as an important function of government management. the crisis may occur in advance to have a full estimate, in advance to prepare for emergency, choose the best response plan, reduce the loss of government and public.

(5) Public crisis rescue mechanism. Perfect public crisis rescue mechanism, to protect people's lives and safety, to maximize the failure of the crisis, we must start from the prevention and emergency two aspects. Prevention, the establishment of rescue and protection mechanism, from the system to ensure the rescue supplies reserves and funds; the establishment of rescue departments, specifically responsible for the rescue work; we should improve the transfer payment and financial management system for the rescue. In response to the crisis, the rapid response to the crisis, through the media to remind people to respond to work, to quickly start the crisis response plan; according to the actual situation, we should adjust the rescue plan; the use of government information network platform and other media timely release of rescue information and disaster; We seek international cooperation and international cooperation, common research and rescue plan.

(6) Public crisis organization and leadership. Mainly refers to the management of national security, responsible for the crisis prevention, crisis detection and control of the functional departments or agencies. Crisis management function department is responsible for a large number of crisis prevention and crisis management, which is the backbone of the crisis management body, and the direct action force of crisis management. Crisis management activities throughout the crisis management. The system of crisis management organization system mainly consists of 5 Application centers, that is, the index decision-making center, the accident scene command center, the support security center, the media center and the information management center. Each center has its own responsibility and construction characteristics, each center is a relatively independent working body, but in the implementation of the task of mutual connection, mutual coordination, showing the system of working state.

(7) Public crisis information security. In the information age, the demand for information is increasing day by day, the speed of information dissemination and utilization rate, and the work efficiency of the various departments of the society have been improved. Create information center, provide information security for crisis management, it can improve the time needed for emergency, effectively protect the safety of life and property. Information management center is an emergency support organization, through the provision of all kinds of information, to guide emergency operations and emergency plans.

(8) Public crisis material support. Material support is the strong backing of crisis management, improve the material reserve and improve the construction of material support system. It has important significance to enhance the rapid response capability and improve the overall level of emergency rescue work. The economic and social benefits of material support are analyzed to ensure the emergency effect, while the operation benefit of the crisis management is maximized, which makes the logistics support the minimum social economic cost, and obtain the maximum benefit. The allocation of material security resources should be the main administrative allocation, which is directly under the jurisdiction of the government as a public crisis management, to play the government's system security and financial resources support.

(9) Legal protection of public crisis. To prevent the huge impact on the country and the social order, the emergency law is needed to implement the emergency law and use administrative power to adjust the social relations among state power, state power and civil rights, civil rights and civil 
rights. Effectively control and eliminate the crisis, restore normal social life order and legal order, safeguard social public interests and citizens' legitimate rights and interests. This requires the government to exercise the power of crisis management. Under the condition of modern law, the administrative power is mainly from five aspects: the scope and boundary of government emergency power, the government's responsibility to determine the conditions for the exercise of emergency powers, and to determine the purpose of the government to exercise the powers of emergency power.

(10) Public crisis performance evaluation. The performance evaluation of public crisis management is the process of implementing public crisis management in the public sector, including the non governmental public organization. In the pursuit of internal management and external effects, quantity and quality, economic factors and ethical political factors, rigid norms and flexible mechanism based on the integration of public crisis management, defining the output of public crisis management. The public crisis management performance evaluation system design, including the public crisis management performance evaluation of the value orientation, evaluation subject, evaluation content, evaluation method, evaluation results of the use of public crisis management performance evaluation of the main content.

\section{Conclusion}

Comprehensively improve the urban crisis management capabilities, to prevent all kinds of emergencies, reduce the loss of disaster, to maintain the sustainable development of economy and society, has become a major issue of the city, and a complex system engineering. Taking the scientific development concept as a guide, drawing on the advanced experience of the developed countries and combining with China's national conditions, this paper constructs the structural system of urban public crisis management, and solves the core problem of urban crisis management. However, due to the characteristics of public crisis and the national conditions of China, we can only rely on the results of this study to guide the practical work, the lack of specific empirical research, but also the need to combine the actual work to refine and improve.

\section{Acknowledgment}

This work is supported by social science fund project of Liaoning province (L12BZZ009): Research on management mechanism for urban public crisis.

\section{References}

[1] Selim Sahin, Serdar Ulubeyli, Aynur Kazaza, "Innovative Crisis Management in Construction: Approaches and the Process," Procedia - Social and Behavioral Sciences, vol. 195, no. 3, pp. 2298-2305, 2015.

[2] Yan Jin, Brooke Fisher Liu, Deepa Anagondahalli, Lucinda Austin, "Scale development for measuring publics' emotions in organizational crises," Public Relations Review, vol. 40, no. 3, pp. 509-518, 2014.

[3] J. Wy, "Public crisis management ability," National School of Administration press, 2005.

[4] Hye-Young Lee, Mi-Na Oh, Yong-Shik Park, Chaeshin Chu, Tae-Jong Son, "Public Health Crisis Preparedness and Response in Korea," Osong Public Health and Research Perspectives, vol. 4, no. 5, pp. 278-284, 2013.

[5] X. M. Zhang, "Public sector crisis management," Renmin University of China press, 2006.

[6] Kyle Lassiter, Amin Khademi, Kevin M. Taaffe, "A robust optimization approach to volunteer management in humanitarian crises," International Journal of Production Economics, vol. 163, no. 5, pp. 97-111, 2015. 